\title{
Managing Risks through Mitigation Strategies: Evidence from Cameroonian Small and Medium Enterprises
}

\author{
Mbiki Mamai ${ }^{1} \&$ Song Yinghua ${ }^{1}$ \\ ${ }^{1}$ School of Management, Wuhan University of Technology, Wuhan, P. R. China 430070 \\ Correspondence: Mbiki Mamai, School of Management, Wuhan University of Technology, Hubei, 430070, \\ China. E-mail: mbikimamai@yahoo.fr
}

Received: November 3, 2016

Accepted: December 6, 2016 Online Published: December 28, 2016

doi:10.5539/ijbm.v12n1p219

URL: http://dx.doi.org/10.5539/ijbm.v12n1p219

\begin{abstract}
While SMEs are widespread and largely influence the economy of nations, its risk management is little known and has received limited attention. With regards to the importance of the managers in these types of companies; the purpose of this paper will be to investigate the relationships that may exist between the profile of the managers of the SMEs and the choice of risk mitigation strategies. By so doing, it turns out that the perception of risk, the managers and their levels of higher education influence the adoption of risk mitigation strategies in SMEs. In addition, the strategies used to manage risk are diversification, cooperation, selection of suppliers and insurance.
\end{abstract}

Keywords: risk mitigation strategies, risk management, owner-managers, SMEs

\section{Introduction}

In all Western economies, small and medium enterprises (SMEs) play an important role. In Canada, for example, the few 2.3 million SMEs are the force driving business activities and job creation and to some extent form the backbone of the economy of those countries. In the European Union, around 99 percent of the economic activities can be traced back to SME, which accounts for two-third of all job creation in the private sector Gama and Geraldes (2012). In Africa and Cameroon in particular, SMEs remain by far the largest sector. It is, therefore, subject to much interest given its economic weight and their contribution to wealth and job creation. Compared to larger companies, SMEs are confronted with several types of risks, benefit less from economies of scale and fewer have access to a wide resources base (Burgstaller and Wagner, 2015). For that, it is important for the enterprise to implement enterprise risk management. Enterprise Risk Management is an approach to measuring and monitoring risk and developing appropriate strategies to manage the risk. According to Önder and Erginn (2012) enterprise risk management is a useful approach to identify and evaluate an organization's decisions and strategies. Risk management may help managers of SMEs to adopt strategies to mitigate risks that they may face. Thus, the risk can be defined as the probability that something undesirable occurring within a given time. The management literature developed a definition of a concept of risk which comprises positive and negative consequences of an event, and may affect the achievement of operational, strategic and financial objectives of company BBA, et al (1999). Risk can be caused by external factors (economic, environmental, social, and political) or by internal factors (human resources, technology) (COSO, 2004). Risk can also be varied by sector of activity and by organizational structure. Thus, risk management should be a priority for SMEs managers. However, companies can manage risk with the help of external sources as networking and internal strategies (Kim and Vonortas, 2014). Companies can also manage risk through their own internal strategic actions. Mitigation strategy involves to handling and dealing with risk, setting the monitoring procedures which ensure that the impact of the risk is minimized. Thus, mitigation strategies become sustainable for survival SMEs operating in such times. So we asked ourselves this question: what is the level of diffusion risk mitigation strategies in Cameroonian SMEs?

The purpose of this paper is to highlight the factors that explain the use of risk mitigation strategies by Cameroonian SMEs and identify the most techniques used to managing risk by these SMEs. 


\section{Literature Review}

\subsection{Concept of Risk in SMEs}

The risk is a concept used to express uncertainty about events and their outcomes that could have a negative impact on the performance of organizations and their goals. Mitchell (1995) defines risk in terms of the probability of loss and the significance of that loss to the enterprise. The capacity of SMEs to identify the risks they could face and to develop strategies making it possible to avoid has its possible risks which will carry out the company to increase its economic growth. However, managers who do not take risk management seriously are confronted with the problem of performance that threatens the continued existence of their businesses which can be equalized to what is called the risk. The sources of risks affecting business management are many. For example, Casualty Actuarial Society (2003) classified risk in different types of hazard risk, financial risk, operational risk, and strategic risk. The COSO ERM model created by the Committee of Sponsoring Organizations of Treadway Commission; the ERM framework categorizes risks within the following types: financial, operational, legal or compliance and strategic risk.

Risk management is based on the selection of strategies to manage the risk. The strategies employed by the enterprise to manage the risk include transferring the risk to another party; this option allows the organization to transfer the risk and associated responsibilities to another entity such as insurance companies. Moreover mitigated risk consists of companies to ensure that preventive measures are put in place to reduce risk.

\subsection{Importance of Risk Management in SMEs}

The importance of SMEs in global economic is not be denied. In all economies, small and medium enterprises play an important role. They are the force driving business activities and job creation. In Cameroon, SMEs represent about $95 \%$ of the population and employing more than half the workforce in the private sector, generate new jobs each year. Apart from that job creation, SMEs contributes also to the development of multinational corporations Aman, Tahir et al. (2011). Despite that, SMEs tend to have a higher failure rate. They also have the advantage over large businesses because they can adapt easily to market conditions and can overcome adverse economic conditions given their informal strategies and flexible structures.

According to Wheelen and Hunger (1999), the higher failure rate is due to informal strategic planning processes and lack of systems to keep track of their performance. SMEs in the manufacturing sector more than any other sector are confronted with increased competition from cheaper manufactured product from others country such as India and China (Bessant and Tidd, 2007), and consequently they are struggling to develop appropriate strategies for competing with them. SMEs need to improve their organizational capabilities by formalizing their systems and structures in order to become more efficient (Bessant and Tidd, 2007) and also they need to make in place efficient risk management process in order to deal with risks and improve their performance. Risk management in manufacturing sector generally focuses on risky situations encountered by the company. Therefore, risk management adds value to the company by ensuring that any exposure to risk is managed. In the literature, too much debate has been involved about the benefit of enterprise risk management. According to Mikes (2011) company are engaged in risk management for two reasons: compliance (for legislation and regulations) or performance (optimization of efficiency and effectiveness). For other researchers, risk management may help to mitigate risks and exploits opportunities. Implementation risk management by a company may reduce potential financial loss, increase business performance, is good business practice and enhance their competitive advantage, which are the potential benefits of risk management. However, other studies Chapman (2003) and Beasley et al., (2009) have suggested that implementations of risk management often fail to bring intended benefits to a company. Despite, Barton et al.; (2002) asserts that the mismanagement of risk has resulted in important damage of a company reputation, decreased shareholder value and also result in significant the financial loss.

It is clear that enterprises need to understand the concept of enterprise risk management because SMEs owner-managers are primarily responsible for the management of their business activities. However, studies carried out by Smit and Watkins (2012) conclude that most risk activities of the SMEs tend to be construed reactively, thereby affecting the availability of enterprise resources in addressing these risks. It is, therefore, essential for SMEs owner-managers to objectively evaluate their actions and to identify the obvious risks. Enterprise risk management provides the owner-managers tools to manage risk; information to enhance operational and strategic decision making and facilitate communication in the overall system.

\subsection{Risk Mitigation Strategies in SMEs}

Although evolving in an environment of perpetual evolution, SMEs must face a multitude of difficulties which 
can emerge in various manners. Owners-managers of SMEs therefore, need to give the importance to the identification, evaluation and controlling of risks. In other words, adapt to the risk management process. By incorporating risk management into its operations, SMEs will be better equipped to deal with the threats. According to Watt (2010), risk management is the process of identification, analyzing and either the acceptance or mitigation of uncertainties in the course of running an entity. Risk reduction is, therefore, important far above long-term financing constraints, as well as on the issue of short-term investments Plourd (2009). Risk mitigation is an action, consciously taken by the top management, to counter in advance, the effects on the business of risk events. Risk mitigation generally can take the form of risk avoidance, risk acceptance, risk transfer and risk reduction. Mitigating risk also implies that SMEs managers adopt strategies that allow to control or minimize the risk perceived within the company. Studies realized by Ntlhane (1995) found out that SMEs owner-managers were not versed in the availability and use of risk mitigation techniques to reduce the adverse effects of risks within the enterprise. Their study concluded that owner-managers of SMEs preferred avoiding risks rather than conceiving risk control methods. So in the literature, there are several ways to manage risk in smaller entities, where risk management is less well developed.

\subsubsection{Collaboration}

Collaboration is one of the effective ways to control the risk within companies. The companies can collaborate with other organizations to form networks by various types of formal agreements such as strategic alliances, marketing promotion, R\&D agreements, technical cooperation agreements, licensing agreements, and subcontracting. By collaboration, the companies can obtain the resources necessary to manage the risk effectively. In the same way, collaboration with competitors can help to prevent the risky operations because sharing information with competitors result in more information about the credit worthiness of prospective customers (Gilmore et al. 2004). For Kim and Vonorta (2014) collaboration is frequently used as a risk mitigation strategy in SMEs mostly to adapting with technology, financial and commercial risks.

\subsubsection{Diversification}

Diversification allows to a company to running more than one businesses as a strategy for the risk management by SMEs. This approach is based on the stating which one should not invest in only one field but rather diversify to avoid bankruptcy. To a certain extent the use of diversification by SMEs as a strategy makes it possible to control risk but the process could be improved if the managers of SMEs were skillful in the choice of the suitable combinations of businesses.

\subsubsection{Insurance}

Insurance is another method applied by SMEs to control risks. This implies transferring the risk to an insurance company. In such a case should the risk occur the insurance company would bring the business to a previous state. In general, SMEs can obtain an insurance against the fire, flooding, property damage and personal injury. In the developing countries like Cameroon, insurance is not an obvious choice or an alternative solution for most SMEs. Nevertheless, studies carried out by Cioccio and Michael (2007) in Australia prove that insurance is the principal tool for risk management. Smit and Watkin (2012) in the South-African context showed that there is a small proportion of owners who use insurance as a technique for risk management. Hollman and Mohammad-Zadeh (1984) added that, in addition to providing protection against the financial losses from such events, insurance may also cover other services for SMEs even if the SMEs does not suffer any loss.

\subsubsection{Choice of the Suppliers}

The choice of the suppliers is another method used by SMEs to manage risks. This implies for SMEs to enter into contracts with various suppliers in order to influence the supplier's behavior which alternatively can attenuate risks. These contracts can be some kind of performance guarantee that requires the constant quality of the products provided to SMEs. Moreover, studies carried out by Ellegaard (2008) show that the managers interviewed reported that they focused on obtaining products from the local markets because this was particularly advantageous for the Western industrial companies. They claimed that a certain number of risks such as the political unrest and the currency issues, and risks related to the cultural differences could be avoided. An SMEs manager by Poba-Nzaou and Raymond (2011) in France and Canada also confirmed the results of Ellegaard (2008) by reporting that its company worked only with suppliers they already knew and who had the same mentality. Consequently, risks related to new suppliers have been avoided.

\subsection{Factors Influencing Adoption Risk Mitigation Strategies}

Business strategy is the outcome of decisions made to help an organization with regard to the respect of the environment, structure and processes that affect its performance. An effective strategy maximizes the efforts of 
the managers within the company. If they understand the strategy, it is must easier to increase their efforts and they are able to apply it to various decisions. The best way to understand and adopt the strategy for managers within SMEs is to involve all the top management in the creation of the strategy. The ability for the management of SMEs to carefully identify the risks that their company could face and to consequently take suitable strategies will certainly lead to successful companies. This thereby contributes to the economic growth of the nation. The strategies that managers of SMEs may adopt within their company for a systematic reduction in the extent of the exposure to the risk are called mitigation strategies. According to Gilmore et al., (2004), while owner-managers recognize that they must encounter certain risky situations, they endeavour to manage these situations so that the risk is minimized. These strategies are influenced by various factors within the company.

\subsubsection{SMEs Managers Risk Perceptions}

The behavior of the firm and their businesses strategies related to managerial decisions are influenced by the manager's risk perception incurred in the performing of any activities, in particular, the strategies related to risk mitigation. Consequently, we can say with Sitkin and Weingart (1995) that decision-making within the organizations is significantly affected by the level of risk perceived by the decision-makers of the firm. However, when the perception of risk is too high, management might no longer believe that it has control over the risk. At this stage, management strategy changes and the firm seeks to relieve itself of some of the control of risk by sharing responsibility and transferring the risk to others organizations.

On this basis, we can say that risk perception of manager affects the choice of the mitigation strategy applied by the firm. In support of this assertion, Ahmed et al. (2002) argued that risk perceptions have a significant impact on the choice of the mode of entry chosen by companies when entering foreign markets. On the other hand, Alrashidi (2016) showed that the decision to export is directly linked with the risk perception of the SMEs managers. In that light, the way that SMEs managers manage risk within the firm is influenced by their perception of risk.

\subsubsection{SMEs Managers' Level of Education}

Enterprise management can consist of the way that a manager makes decisions regarding the management of risk. A higher level of education arms an individual with greater abilities of uncertainty management. At the same time, it makes it easier the calculation of risks and may reveal a reality which is associated with a lower perception of risk. Furthermore, we know that the educational level of the owner-managers of SMEs can help to improve their ability to use skills that are useful in managing a business (Storey, 1994). SMEs having the managers with a high level of education in the key area of society should have a greater propensity to engage in risk mitigation strategies such as cooperation or networking.

\subsubsection{Firm Size}

COSO (2004) mentioned that the size of a firm as one of the characteristics that affect the way how the concepts and principles of COSO framework are most effectively and efficiently implemented. Most of the studies have shown that large companies are more likely to engage in risk management activities because they have the necessary resources for its implementation in contrast to small companies. Yazid et al. (2011) reported that the size of a firm is one of the factors that could possibly influence any firm to eventually implement risk management. Thus compared to the small companies, bigger firms should be more easily engaged in various strategies to manage risks. The lack of reputation for SMEs to cover the transaction costs of strategies leads to adverse selection problems. From the past empirical studies, the frequent measurement for firm size is in terms of employment or a total number of employees in the company. The size of a firm can also be reflected in its total assets (Yazid et al., 2012). We can say firm size is an important characteristic of the enterprise that affects how owner-managers in SMEs manage risks.

\section{Research Methodology}

To meet the specific objectives of our study which is to highlight the factors that affect risk mitigation strategies by SMEs and identify the most techniques used to managing risks. We handed out a questionnaire to SMEs which were the target population of our sample. 182 questionnaires were given either as written documents to companies or electronically clearly indicating the objectives of our research. The 86 answers collected or information gathered through this survey were subjected to statistical analysis (descriptive statistics, logistic regression, cross tabulation) which led to meaningful information which could be interpreted.

From a theoretical point of view and taking into account the Cameroonian context (an exhaustive list of the population not available), we chose the convenience sample method because in this method only the units that we found convenient for some reason were selected. In fact, our investigation was focused on the manufacturing 
companies which agreed to answer our questions. Moreover, taking into account the difficulty in the access to the company's resources of our study and our limited capacity, we were satisfied with the method of the large numbers which, to determine the representativeness of the sample, stipulates that: when the sample size is more than 30 , the most probable value of average of a sample is the average of the population.

The dependent variable or subject of our investigation is noted - "using risk mitigation strategies" and will be measure in using the dichotomic variable which takes the value " 1 " if the company uses risk mitigation strategies and the value " 0 " if otherwise.

The independent variables are defined by:

- $\quad$ Risk perception is defined by the level of risk perceived by the managers;

- Firm Size is a variable which characterizes the company and is measured by the number of employees;

- Level of Education is measured by the educational attainment of the managers

- $\quad$ Previous experience is measured by the years of professional experience the managers;

\section{Results of Data Analysis}

Data Analysis in our investigation led us to the use of risk mitigation strategies by Cameroonian SMEs. It highlights the tools or techniques most used by these companies and the perceptions of the managers of these tools.

\subsection{Choice of the Techniques Uses to Manage the Risk in Cameroonian SMEs}

The Results show us that the strategies most used by the managers in order to manage risks within SMEs are: diversification, cooperation, selection of suppliers and to the lesser extent insurance. With regards to the frequency of use of these techniques to mitigate risk, the cross tabulation Strategies * ERM adoption gives us the following results: (table 1)

Table 1. Strategy * adoption crosstab

\begin{tabular}{|c|c|c|c|c|c|}
\hline \multirow{3}{*}{ Cooperation } & \multicolumn{4}{|c|}{ Adoption risk management } & \multirow{3}{*}{$\begin{array}{l}\text { Total } \\
45\end{array}$} \\
\hline & \multicolumn{2}{|r|}{ No } & \multicolumn{2}{|c|}{ Yes } & \\
\hline & Yes & Count & 33 & 12 & \\
\hline & & Expected Count & 33.5 & 11.5 & 45.0 \\
\hline & & $\%$ within Cooperation & $73.3 \%$ & $26.7 \%$ & $100.0 \%$ \\
\hline & No & Count & 31 & 10 & 41 \\
\hline & & Expected Count & 30.5 & 10.5 & 41.0 \\
\hline & & $\%$ within Cooperation & $75.6 \%$ & $24.4 \%$ & $100.0 \%$ \\
\hline \multirow[t]{6}{*}{ Diversification } & Yes & Count & 42 & 17 & 59 \\
\hline & & Expected Count & 43.9 & 15.1 & 59.0 \\
\hline & & $\%$ within Diversification & $71.2 \%$ & $28.8 \%$ & $100.0 \%$ \\
\hline & No & Count & 22 & 5 & 27 \\
\hline & & Expected Count & 20.1 & 6.9 & 27.0 \\
\hline & & $\%$ within Diversification & $81.5 \%$ & $18.5 \%$ & $100.0 \%$ \\
\hline \multirow[t]{6}{*}{ Insurance } & Yes & Count & 29 & 7 & 36 \\
\hline & & Expected Count & 26.8 & 9.2 & 36.0 \\
\hline & & $\%$ within Insurance & $80.6 \%$ & $19.4 \%$ & $100.0 \%$ \\
\hline & No & Count & 35 & 15 & 50 \\
\hline & & Expected Count & 37.2 & 12.8 & 50.0 \\
\hline & & $\%$ within Insurance & $70.0 \%$ & $30.0 \%$ & $100.0 \%$ \\
\hline \multirow[t]{6}{*}{ Selection of suppliers } & Yes & Count & 29 & 8 & 37 \\
\hline & & Expected Count & 27.5 & 9.5 & 37.0 \\
\hline & & $\%$ within Selection of suppliers & $78.4 \%$ & $21.6 \%$ & $100.0 \%$ \\
\hline & No & Count & 35 & 14 & 49 \\
\hline & & Expected Count & 36.5 & 12.5 & 49.0 \\
\hline & & $\%$ within Selection of suppliers & $71.4 \%$ & $28.6 \%$ & $100.0 \%$ \\
\hline
\end{tabular}

In this table, we see that $28.8 \%$ companies that have adopted risk management within their companies use 
diversification as a strategy, $26.7 \%$ cooperation, $21.6 \%$ selection of suppliers and $19.4 \%$ insurance. This leads us to conclude that the SMEs managers in Cameroon prefer to reduce risk by diversifying their activities. This allows us to identify two types of strategies most used by SMEs in Cameroon: diversification and cooperation. This goes in the same light with the research results achieved by Luper and Kwantum (2012) in Nigeria which revealed that $84 \%$ of SMEs do not cover their company against the risks. Similarly, owner-managers in Cameroon believe that sharing information with competitors is not good for their business though it is important preventing risky situations.

\subsection{Explanatory Factors of Adopting Mitigation Strategies: Contingency and Structural Factors of SMEs}

The variable using risks mitigation strategies can be represented by four items. It would appropriate to determine the most significant item that would represent the variable in question. From the descriptive statistics of the mean and standard deviations for these items, we identified diversification as the significant variable (the lowest standard deviation: 0.467 ; as shown in table 2)

Table 2. Descriptive statistics

\begin{tabular}{llllll}
\hline & $\mathrm{N}$ & Minimum & Maximum & Mean & Std. Deviation \\
\hline Cooperation & 86 & 1 & 2 & 1.48 & .502 \\
Diversification & 86 & 1 & 2 & 1.31 & .467 \\
Insurance & 86 & 1 & 2 & 1.58 & .496 \\
Selection of suppliers & 86 & 1 & 2 & 1.57 & .498 \\
\hline
\end{tabular}

The regression by the Forward Stepwise (Likelihood Ratio) method which we have crossed the using risk mitigation strategy and risk perception of managers, its education level and the size of enterprise give us, the value of Nagelkerke R-Square 0.455 which means that the model explains $45.5 \%$ of the variance in the dependent variable that is here the use of risk mitigation strategy. And the model is true in $81.4 \%$ of cases.

Table 3. Model summary

\begin{tabular}{lll}
\hline-2 Log & Cox \& Snell & Nagelkerke \\
Likelihood & R Square & R Square \\
\hline 93.625 & .144 & .203 \\
82.614 & .247 & .347 \\
73.329 & .324 & .455 \\
\hline
\end{tabular}

As shown in table 4, the risk perception of managers is positively associated with the use of the mitigation strategies with the value of Wald 13.126; we have a strong correlation $\mathrm{B}=2,413$ between the use of the mitigation strategies and the perception of risk by the managers. We can, therefore, say that the risk perception of managers has a high impact on the way that owner-managers use strategies to manage risk within their company. Thus, we can conclude that the higher the perceived risk, the higher the likelihood that managers use mitigation strategies.

Table 4. Variables in the equation

\begin{tabular}{|c|c|c|c|c|c|c|}
\hline & $\mathrm{B}$ & S.E. & Wald & df & Sig. & $\operatorname{Exp}(B)$ \\
\hline Educational level & -1.117 & .402 & 7.721 & 1 & .005 & .327 \\
\hline Employees & -.838 & .394 & 4.524 & 1 & .033 & .433 \\
\hline Risk Perception & 2.413 & .666 & 13.126 & 1 & .000 & 11.173 \\
\hline Constant & -.223 & 1.091 & .042 & 1 & .838 & .800 \\
\hline
\end{tabular}

The education Level of the manager also plays an important role in the use of mitigation strategies. Most the managers with a high level of education will most likely use risk mitigation strategies. The coefficient $\mathrm{B}=$ 1.117, which means that the relationship is negative for the variable level of education. It is, therefore, said that better are the managers who have a high level of education face to the use of risk mitigation strategies. Less it is likely they use strategies. This confirms the cross tabulation level of education * strategy, $100 \%$ of the managers 
who have a level of Masters and $\mathrm{PhD}$ use risk mitigation strategies. This result goes in the same way with the work of Kim and Vonortas (2014), which showed that the level of education of SMEs owners is related to the adopting of risk mitigation strategies, such as networking, and in various strategic actions to mitigate financial, operational and technological risks.

In the same way, larger companies make more use of risk mitigation strategies. The value of Wald $=4.524$ confirms, therefore, this assumption. This is again confirmed when we use descriptive statistics from the cross-tabulations; we realize that some companies that use risk mitigation strategies consist of $100 \%$ of those who employees are greater than 200 people; of $86.4 \%$ of companies with an employee's between 101 and 200 people and $29.2 \%$ only those who employees are lower than 50 people.

\section{Discussion of Results}

The results based on the most used techniques by SMEs owner-managers to manage risks, several techniques are heavily used and the analysis allowed us to identify diversification, monitoring and selection of suppliers. Contrarily to studies carried out by Cioccio and Michael (2007) in Australian, In Cameroonian context, there is a small proportion of owner-managers who use insurance as a tool for risk management. But the services provide by these insurance companies are very important, even sometimes the events against which SMEs have insured does not materialize, insurance may be advantageous because they are forced owner-managers to systemically examine their risks and also usually because managers are not expert in these areas. We found also owner-managers are able to enter into cooperation for managing risks when they perceived the opportunities to gain a more competitive advantage. The results presented in this paper are consistent with those of Gilmore et al. (2004) which stipulate that SMEs often maintain close relationships with existing clients in the hope of doing more business. Delerue and Perez (2009) found that when managers perceive high levels of relational risk, they tend to enter into cooperation relationship and they may manage risks by choosing to forge a relationship with a desirable partner and with that partner to anticipate and deal with risk.

Our research objective was to highlight the factors that influence the adoption of risk mitigation strategies within SMEs the results obtained with logistic regression analysis in this article provide clear support for the importance of risk perception as a crucial factor could affect the ways that managers use mitigation strategies to manage risks within the company; Also because owner-managers in SMEs are the first responsible for the management of their companies activities. SMEs risk management strategies are primarily limited to risk avoidance to some extent risk transfer. So, the development of such strategies should encourage the resolution of the problems and innovative solutions, with the goal to avoid risks or to reduce their impact as much as possible. Indeed, contrarily to what they are saying, owner-mangers in Cameroonian context are most of them risk-averse but their response to opportunity is often to be overconfident, they would especially seek to deal with the problems as they would appear which increase cost. This is explained by the fact that these owner-mangers trust themselves to be able to get more information and expertise concerning risk in order to manage it.

\section{Conclusion and Implications}

In this article, firstly we identify the most used strategies in SMEs to manage risks and secondly to determine the factors that influence the using risk mitigation strategies in Cameroonian SMEs. The results of this research show that the most used strategies are diversification and cooperation or networking. It also helps to know that the majority of SMEs do not use insurance as strategy due to the fact that, insurance is sometimes associated with a considerable cost, and basically covers unexpected events.

About the factors influencing using risk mitigation strategies, we can conclude that: There is a positive relationship between the risk perception of managers and using mitigation strategies. The higher the perceived risk, the higher the likelihood that SMEs will use mitigating strategies to manage risk. It is also shown that the more SMEs managers have a high level of education, the more likely will they use risk mitigation strategies. Moreover, when the number of employees is high, the more the SMEs are prone to use risk mitigation strategies.

The findings reported in this article have several implications for practicing managers that can help in future work. We expected that our study to be beneficial for SMEs owner-managers to develop risk mitigation plans according to the degree and the likelihood of risk perceived and consequently, avoid the risks or to reduce their possible impact on his company. In addition, owner-managers need to be aware that through joint discussion of risk with employees in order to contribute an effective strategies plans and it may result in savings cost by reducing expenses. The findings contribute also for researchers to know how SMEs should develop their management system to deal with the risk because contrary to their counterparts in large enterprises, SMEs are devoid of any risk culture. 
The limitation of our study results from the nature of the available data and a small size of the sample. We require another qualitative study with different factors. Therefore, this topic will need to be investigated further in the future for more thorough analysis.

\section{References}

Acar, E., \& Göc, Y. (2011). Prediction of risk perception by owners' psychological traits in small building contractors. Construction Management and Economics, 29(8), 841-852. http://doi.org/10.1080/01446193.2011.611521

Ahmed, Z. U., Mohamad, O., Tan, B., \& Johnson, J. P. (2002). International risk perceptions and mode of entry: a case study of Malaysian multinational firms. Journal of Business Research, 55(10), 805-813. http://doi.org/10.1016/S0148-2963(00)00220-4

Alquier, B. A. (2012). A method for knowledge capitalization driven by the implementation of a strategic decision support system. IPMA '98 World Congress on Project Management. Ljubjana, Slovenia.

Alquier, B. A. M., \& Tignol, L. M. H. (2006). Risk management in small- and medium-sized enterprises", Production Planning \& Control, 17(3), 273-282. http://doi.org/10.1080/09537280500285334

Alrashidi, Y. A. (2016). The Influence of SMEs Decision-Makers' Individual Characteristics on Risk Perception Associated with Exporting: Evidence from Saudi Arabia. European Journal of Business and Management, $8(2), 51-61$.

Altman, E. I., Sabato, G., \& Wilson, N. (2010). The value of non-financial information in small and medium-sized enterprise risk management. Journal of Credit Risk, 6(2), 95-127.

Aman, O., H., \& Tahir, et al. (2011). The success factors of food small medium entrepreneurs under the one district one industry programme: A case on food manufacturing entrepreneurs in Melaka. Journal of Global Entrepreneurship, 1(1), 44-64.

Azende, T. (2012). Risk management and Insurance of small and medium scale enterprises (SMEs) in Nigeria. International Journal of Finance and Accounting, 1(1), 8-17. http://doi.org/10.5923/j.ijfa.20120101.02

Barton, T. L., Shenkir, W. G., \& Walker, P. L. (2002). Making Enterprise Risk Management Pay Off. Upper Saddle River: FT Press.

Beasley, M., Branson, B., \& Hancock, B. (2009). Report on the Current State of Enterprise Risk Oversight. ERM Initiative at North Carolina State University, Raleigh.

Bessant, J., \& Tidd, J. (2007). Innovation and Entrepreneurship. Wiley: Chichester, UK.

Brustbauer, J. (2014). Enterprise risk management in SMEs: Towards a structural model. International Small Business Journal. http://doi.org/10.1177/0266242614542853

Burgstaller, J., \& Wagner, E. (2015). How do family ownership and founder management affect capital structure decisions and adjustment of SMEs? Evidence from a bank-based economy. The Journal of Risk Finance, 16(1). http://doi.org/10.1108/JRF-06-2014-0091

Chapman, C. (2003) Bringing ERM into Focus. The Internal Auditor, 60, 30-35.

Cioccio, L., \& Michael, E. J. (2007). Hazard or disaster: tourism management for the inevitable in Northeast Victoria. Tourism Management, 28(1), 1-11. .http://doi.org/10.1016/j.tourman.2005.07.015

Committee of Sponsoring Organizations of the Treadway Commission (COSO) (2004). Enterprise Risk Management - Integrated Framework.

Cormican, K. (2014). Integrated Enterprise Risk Management: From Process to Best Practice. Modern Economy, 5, 401-413. http://doi.org/10.4236/me.2014.54039

Ellegaard, C. (2008). Supply risk management in a small company perspective. Supply Chain Management: An International Journal, 13(6), 25-434. http://doi.org/10.1108/13598540810905688

Falkner, E. M. (2015). Risk management in SMEs: a systematic review of available evidence. The Journal of Risk Finance, 16(2), 122-144. http://doi.org/10.1108/JRF-06-2014-0079

Gilmore, A., Carson, D., \& O'Donnell, A. (2004). Small business owner-managers and their attitude to risk”, Marketing Intelligence \& Planning, 22(3), 349-360. http://doi.org/10.1108/02634500410536920

Hélène Delerue Marie Perez. (2009). Unilateral commitment in alliances: an optional behavior. Journal of Management Development, 28(2), 134-149. http://dx.doi.org/10.1108/02621710910932098 
Hiebl, M. R. W. (2013). Risk aversion in family firms: what do we really know? The Journal of Risk Finance, 14(1), 49-70. http://dx.doi.org/10.1108/15265941311288103

Hofmann, M. A. (2009). Interest in enterprise risk management is growing. Business Insurance, 43(18), 14-16.

Hollman, K. W., \& Mohammad-Zadeh, S. (1984). Risk management in small business. Journal of Small Business Management, 22(1), 7-55.

Kim, Y., \& Vonortas, N. S. (2014). Managing risk in the formative years: Evidence from young enterprises in Europe. Technovation, 34(8), 454-465. http://dx.doi.org/10.1016/j.technovation.2014.05.004

Leopoulos, V., Kirytopoulos, K., \& Malandrakis, C. (2006). Risk management for SMEs: Tools to use and how. Production Planning \& Control, 17(3), 322-332. http://dx.doi.org/10.1080/09537280500285136

Luper, I., \& Kwanum, I. M. (2012). Capital structure and firm performance: Evidence from manufacturing companies in Nigeria. Research Journal of Finance and Accounting, 3(5), 151-158.

Marcelino-Sádaba, S., Pérez-Ezcurdia, A., Echeverría Lazcano, A. M., \& Villanueva, P. (2014). Project risk management methodology for small firms. International Journal of Project Management, 32(2), 327-340. http://dx.doi.org/10.1016/j.ijproman.2013.05.009

Mikes, A. (2011). From Counting Risks and Making Risks Count: Boundary-Work in Risk Management. Accounting, Organizations and Society, 36, 226-245. http://dx.doi.org/10.1016/j.aos.2011.03.002

Mitchell, V. W. (1995). Organizational Risk Perception and Reduction: A Literature Review. British Journal of Management, 6, 115-133. http://doi.org/10.1111/j.1467-8551.1995.tb00089.x

Önder, Ş., \& Ergin, H. (2012). Determiners of Enterprise Risk Management Applications in Turkey: An Empirical Study with Logistic Regression Model on the Companies Included in ISE (Istanbul Stock Exchange). Business and Economic Horizons, 7, 19-26.

Plourd, K. (2009). Rethinking risk. CFO Magazine, 66-69.

Poba-Nzaou, P., \& Raymond, L. (2011). Managing ERP system risk in SMEs: A multiple case study. Journal of Information Technology, 26(3), 170-192. http://doi.org/10.1057/jit.2010.34

Sitkin, S. B., \& Weingart, L. R. (1995). Determinants of risky decision-making behavior: A test of the mediating role of risk perceptions and propensity. Academy of Management Journal, 38(6), 1573-1592

Storey, D.J. (1994). Understanding the Small Business Sector. Routledge, UK.

Tatsiopoulos, I., Leopoulos, V., \& Kirytopoulos, K. (2001). Risk as a strategic decision factor for the competitive bidding process in contract manufacturing. Proceedings of the IFIP Conference, Aalborg, Denmark, 100-107.

Watson, G. E. (2004). A situational analysis of entrepreneurship mentors in South Africa. University of South Africa.

Wheelen T. L., \& Hunger J. D. (1999). Strategic Management and Business Policy. Addison-Wesley: Reading, MA

Yolande, S., \& Watkins, J. A. (2004). A literature review of small and medium enterprises (SME) risk management practices in South Africa. African Journal of Business Management, 6(21), 6324-6330. http://dx.doi.org/10.5897/AJBM11.2709

\section{Copyrights}

Copyright for this article is retained by the author(s), with first publication rights granted to the journal.

This is an open-access article distributed under the terms and conditions of the Creative Commons Attribution license (http://creativecommons.org/licenses/by/4.0/). 